\title{
Japan courts US on joint project
}

Tokyo \& Washington

OFFICIALS from Japan's Ministry of International Trade and Industry (MITI) were in Washington last week to sound out the possibility of US participation in a major government-industry project MITI plans to launch next year: a programme to develop a new generation of computers that will mimic the human brain.

The New Information Processing Technology (NIPT) project, known informally as the sixth-generation computer project, will replace Japan's fifth-generation computer project after it ends next March.

When MITI announced that previous project in the early $1980 \mathrm{~s}$, it caught the attention of the rest of the developed world and spawned a series of competing efforts in the United States and Europe, such as the Alvey project in the United Kingdom.

That fifth-generation effort, however, which consumed about $¥ 50,000$ million ( $\$ 370$ million) over the past ten years, has fallen far short of its aims and has not led to a Japanese takeover of the world's computer industry, as some Western governments feared. So this time around, MITI is hoping to attract foreign - and especially US expertise. Not surprisingly, US government officials have been wary about allowing US assistance to MITI's new project.

Officials of MITI's Industrial Electronics Division last week visited the White House Office of Science and Technology Policy, the
Department of Commerce and the State Department to try to encourage US participation. US officials are unwilling to reveal specifics of the meetings, but the basic question that must be answered, one official said, is: "What's in it for us?" The advantages to Japan of having collaboration from IBM or AT\&T Bell Labs are clear; the advantages to the United States are not so obvious.

Tension over the project first arose last year. MITI made a number of discreet overtures to US researchers and representatives of US companies about whether they would be interested in collaboration on the project. For instance, while visiting Japan, Bell Labs president Ian Ross was asked about cooperation on the project during a conversation on a completely different subject.

But such approaches have annoyed the US government, which insists that, because this is a MITI-sponsored project, any contact must be made through official channels. In December, the Japanese agreed not to deal directly with US researchers or companies and to negotiate collaboration on the project under the guidelines of the 1988 US-Japan Science and Technology Agreement.

Those negotiations could take a long time. The only other major project to come under the agreement's umbrella is MITI's proposed Intelligent Manufacturing System (IMS) project (see Nature 347, 320; 1990). MITI has been seeking US support for IMS for more than a year, and so far the two countries have done no more than agree on the "terms of reference" for a feasibility study that has not yet begun.

NIPT will focus on massively parallel computer processing and, in particular, neural network computers and optical computers. And MITI is expected to spend about $\$ 30-\$ 40$ million a year over ten years, says Shunichi Amari of Tokyo University, a member of a committee of more than 60 industrialists and academics that recently completed a two-year study of brain-like computers for the ministry.

Taizo Nishikawa of MITI's Industrial Electronics Division says that unlike the fifth-generation project, which concentrated on one objective, the sixth-generation project will be a research programme consisting of several projects by a number of different research groups both in Japan and overseas. Previous MITI projects have been like attempts to "climb Mount Fuji", he says, but the sixth-generation project will be "like climbing Yatsugatake", a range of eight peaks in Japan.

The next step in the US-Japan negotiations on the project will come in July, when the two countries meet in Tokyo for working-level talks on the science and technology agreement. No decision on US participation is expected before MITI submits a budget request for the first year of the project in late August.

David Swinbanks \& Robert Pool

\section{The private sector offers an alternative}

WHILE the world's attention focuses on MITI's next generation computer project (see above), a group of Japanese academics and industrialists have been try ing to launch an alternative to the sixth generation computer project with private sector funding.

Their initiative, called the Internationa Institute of Novel Computing (IINC), may never get off the ground. But the very fact that some top Japanese companies have been prepared to put money into the project shows a growing movement in Japanese industry to look for alternatives to MITI projects, which, although often seen in the West as a source of Japan's economic might, are viewed in a very different light by Japanese industry.

The IINC initiative was launched last year by the Japan Technology Transfer Association - a non-profit organization funded largely by private industry - with the backing of nine private companies, including Hitachi, Nissan and Nippon Steel Corporation.

The project is led by Hideo Aiso of Keio University and includes many academics who are also involved in MITI's sixth generation project.

The nine companies each donated $¥ 1.8$ million $(\$ 13,000)$ to fund a feasi- bility study of various types of next-generation computing on which IINC might focus, including parallel, optical and neural computing - key targets of MITI's project. When the initiative was announced last September, officials of the Technology Transfer Association said they were confident that many more companies would join the scheme (see Nature 347 , 217; 1990).

But the expected contributors have not materialized, and academics participating in the project suspect that MITI may be to blame. One MITI official, for instance, said "we are very annoyed by IINC". He explained, "They are confusing people because many of the people participating in IINC are also participating in NIPT. I am not saying they should not be allowed to do what they want to do, but it is annoying and confusing." Simply letting companies know that MITI is "annoyed" is probably enough to kill donations without any further action.

Why has such an alternative project arisen? Although no researchers in Japanese private industry or MITI's national laboratories are prepared to say so publicly, many are dissatisfied with the ministry's big national projects.

The projects are inflexible and set rigid goals that must be achieved no matter what the changing circumstances, researchers say. An example is the fifth generation computer project, which set out in 1982 to build in ten years a specific type of parallel computer with 1,000 microprocessors running on logic programming. By the mid-1980s, it was clear that alternative approaches might be better, but changes could not be made. IINC promoters hope to establish a longer-term project with more flexible goals.

So why does industry continue to participate in MITI's projects? The reasons are complex and include the regulatory powers MITI has over industry. One key factor is that during the early post-war era when Japanese industry was in a shambles, MITI did much to revitalize and provide support for industry. Senior executives in Japan's companies still remember those days, and in Japanese society, where obligations for past favours always remain strong, it is very hard for companies to reject MITI propo sals. However, as the senior manage ment of Japanese companies undergoes a generational change in the near future. many predict that MITI's power will wane.

D.S. 